\title{
The comparative effects of intermittent versus continuous energy restriction on anthropometry and cardiometabolic disease risk markers in obese patients utilizing weight loss support services provided by an NHS tier 3 weight management service
}

\author{
R. Antoni ${ }^{1}$, K.L. Johnston ${ }^{3}$, C. Steele ${ }^{2}$, D. Carter ${ }^{2}$, M.D. Robertson ${ }^{1}$ and M. Capehorn ${ }^{2}$ \\ ${ }^{1}$ Nutrition, Metabolism and Diabetes Research Group, Faculty of Health and Medical Sciences, \\ University of Surrey, Guildford, GU2 7WG, \\ ${ }^{2}$ Rotherham Institute for Obesity, Clifton Medical Centre, The Health Village, Doncaster Gate, Rotherham, S651DA \\ and \\ ${ }^{3}$ Lighterlife UK Ltd, Cavendish House, Parkway, Harlow Business Park, Essex, CM19 5QF
}

Weight loss through continuous energy restriction (CER) has notoriously poor outcomes. Intermittent energy restriction (IER) as a method of weight loss has attracted considerable attention ${ }^{(1)}$ due to its purported superior metabolic benefits and because short spells of severe energy restriction alternated with days of habitual intake may be easier to follow. However, findings from previous weight loss comparison studies have been variable ${ }^{(1)}$. This is the first intervention trial comparing IER versus CER for weight loss and improvement in cardiometabolic outcomes in obese patients registered with an NHS tier 3 weight management setting Rotherham Institute for Obesity (RIO)

This trial was granted ethical approval by the South Yorkshire NRES committee (14 YH 0018). 200 ( $\mathrm{n}=47$ male) obese patients who had been referred via their GP to the RIO weight loss clinic, volunteered to participate and in accordance with standard RIO care were allowed to choose which of the two dietary intervention they wished to follow. The IER intervention was a formula based very low-energy diet (LighterLife Fast) consisting of $2638 \mathrm{~kJ}$ two days per week alongside five days unrestricted healthy eating $(\mathrm{n}=100)$ and the CER intervention was a healthy daily diet $2510 \mathrm{~kJ}$ below estimated energy requirements $(n=100)$. Anthropometry and established fasting cardiometabolic disease risk markers were measured before and after a six-month intervention period. Completer data were analysed using analysis of covariance to compare changes between groups, with baseline levels, age, gender and co-morbidities included as covariates. Paired t-tests were used for within-group comparisons.

27 IER patients and 39 CER patients completed the study. Mean (standard deviation) weight-loss loss was 5 (5.6) \% in the IER group and $3(4.0) \%$ in the CER group ( $\mathrm{p}=0.046)$. Weight-loss was accompanied by significantly greater reductions in fat mass (bioimpedance) in the IER group $(11[11.8] \%$ vs. $2[10 \cdot 2] \%, \mathrm{p}=0 \cdot 010)$, as well as waist circumference $(4[5 \cdot 2] \%$ vs. $2[4 \cdot 0] \%, p=0 \cdot 047)$.

Table 1. Changes in fasting parameters over six months. * Significant within-group.

\begin{tabular}{|c|c|c|c|c|c|c|c|c|c|}
\hline & \multicolumn{4}{|l|}{ IER } & \multicolumn{4}{|l|}{ CER } & \multirow[b]{3}{*}{$P$ value } \\
\hline & \multicolumn{2}{|l|}{ Pre } & \multicolumn{2}{|l|}{ Post } & \multicolumn{2}{|l|}{ Pre } & \multicolumn{2}{|l|}{ Post } & \\
\hline & Mean & $\mathrm{SD}$ & Mean & SD & Mean & SD & Mean & SD & \\
\hline Glucose $\mathrm{mmol} / \mathrm{L}$ & $5 \cdot 1$ & 0.7 & 4.9 & 0.7 & $5 \cdot 3$ & $1 \cdot 2$ & $5 \cdot 3$ & 1.5 & $0 \cdot 120$ \\
\hline Insulin $\mathrm{uU} / \mathrm{mL}$ & $24 \cdot 2$ & $10 \cdot 8$ & $19 \cdot 1$ & 11.4 & $28 \cdot 6$ & $20 \cdot 2$ & $25 \cdot 3$ & $11 \cdot 8$ & 0.019 \\
\hline Total chol mmol/L & $4 \cdot 7$ & $0 \cdot 9$ & $4 \cdot 6$ & 0.7 & $4 \cdot 7$ & $1 \cdot 0$ & $4 \cdot 7$ & $1 \cdot 0$ & $0 \cdot 824$ \\
\hline $\mathrm{LDL} \mathrm{mmol} / \mathrm{L}$ & $2 \cdot 9$ & 0.7 & $2 \cdot 9$ & $0 \cdot 7$ & $2 \cdot 9$ & $1 \cdot 0$ & $2 \cdot 8$ & $1 \cdot 0$ & 0.486 \\
\hline $\mathrm{HDL} \mathrm{mmol} / \mathrm{L}$ & $1 \cdot 16$ & $0 \cdot 3$ & 1.25 & $0 \cdot 2^{*}$ & $1 \cdot 16$ & $0 \cdot 3$ & $1 \cdot 18$ & $0 \cdot 3$ & 0.029 \\
\hline $\mathrm{TAG} \mathrm{mmol} / \mathrm{L}$ & 1.4 & 0.5 & 1.2 & $0.4^{*}$ & 1.4 & $0 \cdot 6$ & 1.4 & $0 \cdot 7$ & 0.006 \\
\hline Systolic BP mmHg & 129 & 11 & 122 & $11^{*}$ & 117 & 11 & 123 & $12 *$ & $<0 \cdot 001$ \\
\hline Diastolic BP $\mathrm{mmHg}$ & 77 & 8 & 73 & $7^{*}$ & 74 & 9 & 71 & 7* & 0.937 \\
\hline
\end{tabular}

In summary, both CER and IER groups achieved or surpassed, respectively, the clinically significant weight-loss threshold identified by the National Institute of Clinical Excellence. Indeed, both groups exhibited improvements in at least one cardiometabolic disease risk marker. Changes in body weight and adiposity were greater among IER patients and the superiority of IER in reducing levels of fasting insulin and triacylglycerol is in line with some previous research ${ }^{(2-3)}$. The superior changes in HDL cholesterol and systolic blood pressure observed with IER are novel to this study. Further research into how these findings translate over the longer term, as well as the factors influencing the acceptability of and adherence to IER, are required.

1. Antoni R. et al. (2017) Proc Nutr Soc (in press)

2. Harvie MN, Pegington M, Mattson M et al. (2011) Int J Obes 35 714-727

3. Varady K, Bhutani S, Klempel MC et al. (2011) Lipids Health Disease 10119 